\title{
The age-related deficit in LTP is associated with changes in perfusion and blood-brain barrier permeability
}

\author{
Christoph W. Blau, Thelma R. Cowley*, Joan O'Sullivan, Belinda Grehan, Tara C. Browne, \\ Laura Kelly, Amy Birch, Niamh Murphy, Aine M. Kelly, Christian M. Kerskens, \\ Marina A. Lynch \\ Trinity College, Institute of Neuroscience, Trinity College, Dublin, Ireland
}

Received 18 April 2011; received in revised form 22 September 2011; accepted 30 September 2011

\begin{abstract}
In view of the increase in the aging population and the unavoidable parallel increase in the incidence of age-related neurodegenerative diseases, a key challenge in neuroscience is the identification of clinical signatures which change with age and impact on neuronal and cognitive function. Early diagnosis offers the possibility of early therapeutic intervention, thus magnetic resonance imaging (MRI) is potentially a powerful diagnostic tool. We evaluated age-related changes in relaxometry, blood flow, and blood-brain barrier (BBB) permeability in the rat by magnetic resonance imaging and assessed these changes in the context of the age-related decrease in synaptic plasticity. We report that T2 relaxation time was decreased with age; this was coupled with a decrease in gray matter perfusion, suggesting that the observed microglial activation, as identified by increased expression of CD11b, MHCII, and CD68 by immunohistochemistry, flow cytometry, or polymerase chain reaction (PCR), might be a downstream consequence of these changes. Increased permeability of the blood-brain barrier was observed in the perivascular area and the hippocampus of aged, compared with young, rats. Similarly there was an age-related increase in CD45-positive cells by flow cytometry, which are most likely infiltrating macrophages, with a parallel increase in the messenger mRNA expression of chemokines IP-10 and MCP-1. These combined changes may contribute to the deficit in long-term potentiation (LTP) in perforant path-granule cell synapses of aged animals.
\end{abstract}

(C) 2011 Elsevier Inc. All rights reserved.

Keywords: Microglial activation; Long-term potentiation (LTP); Age; magnetic resonance imaging (MRI); blood-brain barrier (BBB); Hippocampus; T2 relaxation time; Perfusion imaging

\section{Introduction}

The age-related deterioration in synaptic function is associated with neuroinflammatory changes which are typified by activation of both microglia and astrocytes (Lynch, 2010). Emerging evidence suggests that these changes may be evaluated noninvasively by magnetic resonance imaging (MRI). Thus local increases in brain T1 relaxation time have been linked with acute astrocyte activation (Anderson et al.,

C. Blau and T. Cowley contributed equally to this work.

* Corresponding author at: Trinity College-University of Dublin, Trinity College Institute of Neuroscience, Dublin, Ireland. Tel.: +353 1896 8477; fax: +35318963545 .

E-mail address: tcowley@tcd.ie (T.R. Cowley).
2006; Sibson et al., 2008), while the age-related increase in glial fibrillary acidic protein (GFAP) expression and immunoreactivity was also accompanied by increased $\mathrm{T} 1$ relaxation time (Cowley et al., 2010). Decreased T2 relaxation time has been correlated with microglial activation in a rat model of ischemic stroke (Justicia et al., 2008). T2 also decreases with age in humans (Siemonsen et al., 2008) although the evidence indicates that its effect is more profound in advanced age. However, T1 and T2 relaxation times are also affected by several factors including localized edema, altered vascular dynamics, and axonal loss (Fabene et al., 2003; Grohn et al., 2000; van Walderveen et al., 1998).

An age-related decrease in cerebral blood flow has been reported using arterial spin labeling (ASL) whereby the 
mean transit time (MTT) and capillary transit time (CTT) of magnetically labeled blood water can be measured by MRI (Kelly et al., 2010; Mitschelen et al., 2009). Consistent with this, Small and colleagues reported an age-related decrease in brain oxygenation, particularly in the hippocampus (Small et al., 2004). These changes are likely to have a significant effect on synaptic function (Reitz et al., 2009).

The factors which trigger the age-related activation of glia are not known, although a change in the balance between pro- and anti-inflammatory cytokines, as well as dysregulation of antioxidative processes, which are likely to promote activation, have been reported (Nolan et al., 2005; Roy et al., 2008). In addition, glial cell activation by infiltrating peripheral cells has been reported recently (McQuillan et al., 2010; Murphy et al., 2010). The evidence suggests that there is minimal infiltration of peripheral cells in the healthy brain; this is probably primarily due to the fact that expression of chemotactic agents is low, because migration of cells appears to be controlled mainly by expression of chemokines and adhesion molecules and their receptors. However, there is a marked increase in cell infiltration following trauma (Shichita et al., 2009) and in neurodegenerative conditions (Stone et al., 2009; Togo et al., 2002) when the blood-brain barrier (BBB) is breached and when expression of chemotactic agents is increased.

Here we set out to assess whether the age-related increase in microglial activation, as indicated by cell surface markers CD11b, MHCII (OX6), and CD68, was accompanied by changes in $\mathrm{T} 2$ relaxation time. Furthermore, we aimed to evaluate whether these changes were associated with evidence of altered perfusion (assessed by ASL) and BBB permeability (using the MRI contrast agent meglumine gadopentate). These measures may provide a further understanding of the factors which contribute to the agerelated decrease in hippocampal synaptic plasticity, assessed by the ability to sustain long-term potentiation (LTP). The evidence suggests that perfusion and BBB permeability are altered in aged rats compared with young rats, particularly in the hippocampus, and that these modifications are linked with a decrease in $\mathrm{T} 2$ relaxation time. It is proposed that one consequence of these combined agerelated changes is a decrease in the ability of aged rats to sustain LTP.

\section{Methods}

\subsection{Animals}

Groups of young (3-5 months old) and aged (20-26 months old) male Wistar rats (B\&K Universal, Hull, UK) were housed in the BioResources Unit, Trinity College Dublin under standard conditions (2-3 per cage; 12-hour light-dark cycle; $22{ }^{\circ} \mathrm{C}-23{ }^{\circ} \mathrm{C}$; food and water ad libitum). For some experiments, male Wistar rats of intermediate ages (14-26 months old and 18-20 months old) were also used. Experiments were performed under license and in accordance with ethical guidelines.

\subsection{Magnetic resonance imaging}

MRI was carried out on a dedicated rodent Bruker Biospec system (Bruker Biospin, Germany) with a 7 Tesla magnet and a $30 \mathrm{~cm}$ diameter core, equipped with a $20 \mathrm{~cm}$ actively-shielded gradient system. A pair of actively decoupled $12 \mathrm{~cm}$ Helmholtz transmitters, and $3 \mathrm{~cm}$ surface quadrature receive coils (Bruker Biospin), were used for signal transmission and reception respectively. The machine was connected to a workstation running ParaVision 4.0 software (Bruker Biospin) for data reconstruction and analysis.

Animals were anesthetized with $4 \%$ isoflurane (Isoflo; Abbott Animal Health, Maidenhead, UK) in 100\% oxygen and maintained with $1.5 \%-2 \%$ isoflurane administered by facemask in either $100 \%$ oxygen, or, in the case of the perfusion imaging, a 30\%:70\% oxygen:nitrogen mix; the depth of anesthesia was monitored using respiratory rate and heart rate and controlled by altering isoflurane concentration. To carry out MRI, animals were placed in a custombuilt magnetic resonance (MR)-compatible Perspex rat cradle, positioned using a bite bar and ear supports with the receive coil placed over the skull. Accurate positioning was ensured by acquiring an initial pilot image using a fast gradient echo scan and a single-slice high contrast scan taken at the isocenter of the B0 magnetic field to ensure that the imaging region was centered at bregma $-3.60 \mathrm{~mm}$ and allow consistent imaging of the cortical and hippocampal regions of interest (ROIs).

\subsection{Arterial spin labeling}

The ASL sequence consisted of a 5-second preparation interval containing the inversion pulse, followed by a snapshot fast low-angle shot (FLASH) image acquisition (echo time $[\mathrm{TE}]=3.5 \mathrm{~ms}$, repetition time $[\mathrm{TR}]=11 \mathrm{~ms}$, flip angle $[\mathrm{FA}]=30^{\circ}$, bandwidth $[\mathrm{BW}]=25 \mathrm{kHz}$, number of repetitions $[\mathrm{NR}]=6$, slice thickness $=1.6 \mathrm{~mm}$, number of slices $=1$, field of view $[\mathrm{FOV}]=3.0 \times 3.0 \mathrm{~cm}$, matrix $=$ $128 \times 64$, acquisition time $=2$ minutes, 34 seconds per repetition [Kerskens et al., 1996]). Flow-induced fast adiabatic passage of inflowing inverted arterial spins was performed using a rectangular pulse, inverting arterial spins that then travel to the imaging plane (Dixon et al., 1986; Kelly et al., 2009). The inversion pulse radio frequency power $(-22 \mathrm{~dB})$ and offset frequency $(-12 \mathrm{kHz})$ were determined to give optimal perfusion contrast by achieving inversion $20 \mathrm{~mm}$ proximal to the imaging plane. Control images with the offset frequency reversed $(12 \mathrm{kHz})$, in which inflowing spins were left undisturbed, were also acquired, in an interleaved fashion. Six repetitions of each image type were acquired for signal averaging, and corresponding pairs of labeled and control images were subtracted to provide perfusion-weighted maps. A theoretical 
model to facilitate the quantification of cerebral perfusion with ASL (Kelly et al., 2010) was applied to the data. The model uses a bolus-tracking ASL sequence to provide 11 data points on a signal-time curve of the passage of a 3 -second bolus through the imaging slice, and yields values for the MTT, CTT, and relative cerebral blood volume of labeled water (rCBV) in a user-defined region of interest.

\section{3. $T 1$ and $T 2$ relaxometry}

A rapid acquisition with relaxation enhancement (RARE) and with variable repetition time (RARE-VTR) scan was used to calculate $\mathrm{T} 1$ relaxation times $(\mathrm{TE}=$ $12.637 \mathrm{~ms}, \mathrm{TR}=300,589.116,942.255,1396.084$, 2031.981, 3103.081, and $8000 \mathrm{~ms}, \mathrm{FA}=180^{\circ}, \mathrm{BW}=100$ $\mathrm{kHz}, \mathrm{RARE}$ factor $=4$, slice thickness $=1.5 \mathrm{~mm}$, number of slices $=1, \mathrm{FOV}=3.0 \times 3.0 \mathrm{~cm}$, matrix $=128 \times 128$; giving a resolution of $234 \times 234 \times 1500 \mu \mathrm{m}$; and an acquisition time of 8 minutes, 43 seconds). A multislice multiecho (MSME) scan was used to calculate T2 relaxation times (echo spacing $=8.06 \mathrm{~ms}$, number of echoes $=12, \mathrm{TR}=$ $2000 \mathrm{~ms}, \mathrm{FA}=180^{\circ}, \mathrm{BW}=100 \mathrm{kHz}$, slice thickness $=1.5$ $\mathrm{mm}$, number of slices $=5, \mathrm{FOV}=3.0 \times 3.0 \mathrm{~cm}$, matrix $=$ $128 \times 128$, acquisition time $=4$ minutes, 16 seconds). A fast imaging with steady-state precession (FISP) scan (TE $=1.5$ $\mathrm{ms}, \mathrm{TR}=3.0 \mathrm{~ms}, \mathrm{FA}=60^{\circ}, \mathrm{BW}=150 \mathrm{kHz}, \mathrm{NR}=60$, inversion time $=6 \mathrm{~ms}$, slice thickness $=1.5 \mathrm{~mm}$, number of slices $=5, \mathrm{FOV}=3.0 \times 3.0 \mathrm{~cm}$, matrix $=128 \times 128$, acquisition time $=5$ minutes, 20 seconds) was performed from which $\mathrm{T} 1$ and $\mathrm{T} 2$ relaxation times were derived using an in-built macro in the scan acquisition software (Schmitt et al., 2004). To allow colocalization of relaxation times, the 3 scans shared the same geometry. Additionally, a "slice scout" anatomical RARE scan ( $\mathrm{TE}=12 \mathrm{~ms}$, TR $=6250 \mathrm{~ms}$, RARE partitions $=8$, acquisition time 55 seconds) using the same matrix, field of view, and slice thickness as in the relaxometry experiments. This was used as the template for selection of the ROI from which local mean $\mathrm{T} 1$ and $\mathrm{T} 2$ relaxation times were calculated.

\subsection{Contrast agent MRI}

For analysis of BBB permeability, using the contrast agent meglumine gadopentate (Magnevist, HE Clissmann, Dublin, Ireland), tail veins were bilaterally cannulated to allow intravenous administration of the contrast agent and the propofol anesthetic. Animals were allowed to recover from isoflurane anesthesia until spontaneous movement occurred, and then reanesthetized with a single bolus of intravenous propofol (7.5 mg; Rapinovet, MSD Animal Health, Tallaght, Ireland) and, after 6 minutes, continuously infused with propofol, $45 \mathrm{mg} \mathrm{kg}^{-1}$ hour $^{-1}$ while breathing room air (Griffin et al., 2010). Propofol was used to maintain anesthesia in these experiments because it has been reported that isoflurane opens the BBB (Tétrault et al., 2008).

A fast T1-weighted fast low-angle shot sequence $(\mathrm{TE}=$ $2.5 \mathrm{~ms}, \mathrm{TR}=4.5 \mathrm{~ms}, \mathrm{FA}=30^{\circ}, \mathrm{BW}=100 \mathrm{kHz}, \mathrm{NR}=60$, slice thickness $=1.5 \mathrm{~mm}$, number of slices $=11, \mathrm{FOV}=$ $3.0 \times 3.0 \mathrm{~cm}$, matrix $=128 \times 128$, acquisition time $=15$ minutes [Kerskens et al., 1996]) with T2*-crusher gradients was developed to assess blood brain barrier permeability to the contrast agent meglumine gadopentate. The tail vein catheter was flushed with saline, and the cannula and tubing were loaded with the contrast agent. Five repetitions of the scan were acquired prior to delivery of a bolus of contrast agent $(0.2 \mathrm{mmol} / \mathrm{kg})$ and scanning continued for 15 minutes. Following scanning, animals were allowed to recover on a heat pad, breathing room air, until they were sufficiently awake to be reintroduced to their home cage.

\subsection{MRI analysis}

MRI data were analyzed using the data acquisition and analysis software, ParaVision (Bruker Biospin), and scripts written in Interactive Data Language (IDL; Exelis Visual Information Solutions UK, Bracknell, UK) software. For T2 relaxation time analysis, a voxel-wise linear fitting to the logarithm of the echo train decay was performed using a region of interest mask superimposed on a high resolution scan. For T1 relaxation time analysis, a voxelwise least squares curve fit of the signal recovery curve was performed and the same region of interest mask was used. ASL data were analyzed in IDL: the MTT and CTT were quantified using the previously described bolus tracking ASL method (Kelly et al., 2010). Briefly, a noncompartmental model of cerebral perfusion was fitted to the bolus tracking ASL data. The MTT and CTT were calculated from the first and second statistical moments of the signal-time curves, respectively. The rCBV was also calculated from the amplitude of the fitted curve, which is directly proportional to the area under the curve (Kelly et al., 2010). This parameter was therefore used to estimate the rCBV in the ROI. Contrast MRI data were analyzed in IDL: the average signal intensity change in the whole dataset was plotted against time, to determine the iteration at which the bolus first became detectable on the dataset. ROI were drawn on the first image of the dataset, and the progression of the logarithm of the contrast change, compared with baseline levels, was extracted and normalized to the average of the precontrast agent signal intensity in that region. Because the animals received the bolus of contrast agent in situ, the positioning of the pre- and postcontrast scans was identical enabling anatomically identical ROIs to be evaluated over time. A standard stereotaxic atlas (Paxinos and Watson, 2004) was used to ensure that the same ROIs were assessed in young and aged rats and all ROIs were drawn on high resolution scans and transferred to the contrast-enhanced datasets of the same animals.

\subsection{Analysis of LTP}

Rats were allowed to recover for at least 48 hours after MRI scanning before LTP was assessed in vivo. Animals were anesthetized by intraperitoneal injection of urethane 
(1.5 $\mathrm{g} / \mathrm{kg})$ and, if necessary, a top-up dose of urethane (maximum dose $2.5 \mathrm{~g} / \mathrm{kg}$ ) was given to achieve deep anesthesia as indicated by the absence of a pedal reflex. LTP was assessed in perforant path-granule cell synapses as previously described (Loane et al., 2009). Briefly, a bipolar stimulating electrode and a unipolar recording electrode were positioned in the perforant path $(4.4 \mathrm{~mm}$ lateral to lambda) and in the dorsal cell body region of the dentate gyrus (2.5 mm lateral and $3.9 \mathrm{~mm}$ posterior to bregma). Test shocks were delivered at 30-second intervals, and after a stabilization period, responses were recorded for 10 minutes before and 45 minutes after tetanic stimulation ( 3 trains of stimuli; $250 \mathrm{~Hz}$ for $200 \mathrm{~ms} ; 30$ seconds intertrain interval). Rats were killed by decapitation at the end of the period of electrophysiological recording and the brains were rapidly removed. One portion of the brain was stored in Tissue Tek OCT (Sakura Finetek Europe B.V., Alphen aan den Rijn, The Netherlands) at $-80{ }^{\circ} \mathrm{C}$ and used for preparation of cryostat sections and subsequent immunohistochemical analysis of CD11b and CD68. The hippocampus and cortex were dissected from the remaining brain tissue and placed in RNAlater (Applied Biosystems, Warrington, UK) to ensure that the integrity of the ribonucleic acid (RNA) was maintained for later gene expression analysis.

\subsection{Analysis of CD11b, CD68, IP-10, and MCP-1 mRNA}

We also assessed age-related changes in microglial activation by evaluating messenger (m) mRNA expression of markers of activation, CD11b and CD68, and the chemokines IP-10 and MCP-1. RNA was extracted from hippocampal tissue using a NucleoSpin RNAII isolation kit (Macherey-Nagel Inc., Düren, Germany) and concentrations were equalized to $1 \mu \mathrm{g}$ prior to cDNA synthesis using a high capacity cDNA RT Kit (Applied Biosystems), according to the manufacturer's instructions. Equal concentrations of cDNA were used for RT-polymerase chain reaction (PCR) amplification. Real-time polymerase chain reaction primers were delivered as "Taqman Gene Expression Assays" containing forward and reverse primers, and a FAM-labeled MGB TaqMan probe for each gene (Applied Biosystems, UK) as described previously (Downer et al., 2010). The assay IDs were as follows: CD11b (Rn00709342_ m1), CD68 (Rn01495631_m1), IP-10 (Rn00594648_m1), and MCP-1 (Rn00580555_m1). Gene expression was calculated relative to the endogenous control samples ( $\beta$-actin) to give a relative quantification (RQ) value $\left(2^{- \text {DDCT }}\right.$, where CT is threshold cycle).

\subsection{CD1 $1 b$ and CD68 immunohistochemical staining}

To assess CD11b imunohistochemistry by light microscopy brain sections were thawed, kept at room temperature for 30 minutes, fixed using ice-cold alcohol and washed in Tris-buffered saline (TBS, $\mathrm{pH} 7.5$ ). The sections were incubated in blocking solution (10\% normal horse serum (Vector Laboratories Ltd., Peterborough, UK) and $4 \%$ bo- vine serum albumin, (BSA; Sigma-Aldrich Ireland Ltd., Arklow, Ireland), in TBS) for 30 minutes at room temperature and overnight in anti-CD11b primary antibody solution (1/100 antibody in 2\% BSA/TBS; AbD Serotec, Kidlington, UK). Negative controls were incubated in $2 \%$ BSA in TBS. The sections were washed, incubated in the secondary antibody solution (1/200 in 2\% BSA/TBS; IgG antimouse biotinylated; Vector Laboratories Ltd., Peterborough, UK; 1 hour; room temperature). The sections were washed, endogenous peroxidases were blocked by incubating in $0.3 \%$ hydrogen peroxide in TBS for 15 minutes and sections were washed again and incubated in $\mathrm{ABC}$ reagent ( 2 drops of A/B in $5 \mathrm{~mL}$ TBS; Vector Laboratories Ltd.) for 1 hour at room temperature. Sections were washed, incubated in DAB stain (Dako, USA) for 10 minutes and this reaction was stopped by washing the slides with double deionized water. The sections were counterstained by incubating in the presence of methyl green (Sigma-Aldrich Ireland Ltd.) for 10 minutes, dehydrated by submerging the slides in a series of alcohols, cleared in xylene, mounted in DPX (p-xylene-bis-pyridinium bromide) and stored for later examination.

To assess CD68 immunohistochemistry, sections were permeabilized for 5 minutes with Triton X-100 surfactant, (Sigma-Aldrich Ireland Ltd.) and nonspecific interactions were blocked (10\% normal goat serum (Vector Laboratories Ltd.), in PHEM buffer (60 mM PIPES, 25 mM HEPES, 10 mM EGTA, 2 mM MgCl 2, pH 6.9; Sigma-Aldrich Ireland Ltd., Arklow, Ireland) containing 1\% BSA for 4 hours at room temperature. Sections were incubated overnight in primary antibody solution (1/200 anti-CD68 antibody raised in mouse in $1 \%$ normal goat serum in PHEM). Negative controls were incubated in 1\% normal goat serum in PHEM alone in the presence of a concentration-matched control anti-IgG antibody. Sections were rinsed 3 times in PHEM, incubated in flourescein isothiocyanate (FITC)-conjugated secondary antibody for 2 hours at room temperature in the dark and washed. Slides were mounted with DAPI nucleic counterstain enhanced mountant (Vector Laboratories Ltd.) and coverslipped. A thin line of nail polish was applied around the coverslip to further stabilize it, and slides were stored at $4{ }^{\circ} \mathrm{C}$.

\subsection{Preparation of cells from young and aged rats and flow cytometric analysis}

In one series of experiments, we used flow cytometry to assess age-related changes in expression of MHCII on $\mathrm{CD}_{11} \mathrm{~b}^{+}$cells as an indicator of microglial activation, and expression of CD45 on $\mathrm{CD}_{11 b^{+}}$cells as an indicator of macrophage infiltration. To do so, young rats (4-6 months; $n=8)$ and aged rats (24-26 months; $n=6)$ were transcardially perfused with $200-300 \mathrm{~mL}$ saline before tissue was harvested. In this case, brain tissue was cross-chopped and enzymatically digested in $5 \mathrm{~mL}$ Krebs buffer containing $10 \%$ collagenase D and $1 \%$ DNase, in a humidified incu- 
bator at $37{ }^{\circ} \mathrm{C}, 95 \%$ air and $5 \% \mathrm{CO}_{2}$ for 30 minutes. Tissue was flushed through a 70- $\mu \mathrm{m}$ cell strainer using Dulbecco's modified Eagles medium (DMEM; Gibco, Invitrogen, Ireland) supplemented with $10 \%$ fetal calf serum (FCS) and $1 \%$ penicillin/streptomycin (Invitrogen). The resultant single cell suspension was centrifuged $(300 \mathrm{~g}, 5$ minutes, room temperature) and the pellet was resuspended and incubated for 30 minutes in $5 \mathrm{~mL}$ complete DMEM containing $0.5 \mathrm{M}$ sucrose and 10\% wt/vol PEG-1000 (Fluka, UK). Samples were centrifuged at $300 \mathrm{~g}$ for 5 minutes at $4{ }^{\circ} \mathrm{C}$ and resuspended in flow cytometry buffer (phosphate-buffered saline, $137 \mathrm{mM} \mathrm{NaCl}, 8.1 \mathrm{mM} \mathrm{Na}_{2} \mathrm{HPO}_{4}, 1.5 \mathrm{mM} \mathrm{KH} \mathrm{PO}_{4}, 2.7$ $\mathrm{mM} \mathrm{KCl} ; \mathrm{pH} 7.4$ ) containing $2 \%$ FCS and $0.1 \%$ sodium azide; hereafter referred to as FCM buffer) and washed 3 times to remove DMEM. Cell suspensions were blocked in FCM buffer containing 50\% FCS for 15 minutes at $4{ }^{\circ} \mathrm{C}$, washed as before to remove FCM buffer, and stained with mouse anti-rat CD11b-Alexa Fluor 647 (AbD Serotec), mouse anti-rat CD45-Alexa Flour 488 (AbD Serotec) and mouse anti-rat OX6-PerCP (BD Pharmingen, BD Bioscience, Oxford, UK) for 30 minutes at $4{ }^{\circ} \mathrm{C}$ in the dark. Cell suspensions were washed and the number of CD11b-positive cells expressing CD45 or OX6 (MHCII) was analyzed using a DakoCytomation (Dublin, Ireland) CyAn ADP flow cytometer and Summit software V4.3.

\subsection{Statistical analysis}

The data were assessed using Student $t$ tests for independent means, 1-way analysis of variance (ANOVA) for more than 2 groups or where time and age were factors a 2-way ANOVA was used. Post hoc Newmann-Keuls tests were used to compare means. Correlations were performed and Pearson's $r$ is reported.

\section{Results}

Analysis of MTT in propofol-anesthetized rats revealed that it was significantly increased in the hippocampus and cortex of aged, compared with young, rats $(* p<0.05$; ${ }^{* *} p<0.01$; Student $t$ test for independent means; Fig. 1a and c). Similarly, analysis of CTT revealed an age-related increase in both brain areas (** $p<0.01$; *** $p<0.001$; Student $t$ test for independent means; Fig. $1 \mathrm{~b}$ and d). These data concur with previous findings indicating a generalized decrease in cerebral perfusion with age (Mitschelen et al., 2009), which has been associated with cognitive decline (Murphy et al., 2008) and with impairment in synaptic plasticity (Lin et al., 2010). To evaluate whether the changes in MTT and CTT described here were associated with any deficits in synaptic plasticity, we assessed LTP in perforant path-granule cell synapses and show that the mean amplitude of the population spike was significantly decreased following the tetanic stimulation in aged, compared with young, rats ( $p<0.001$; ANOVA; Fig. $2 \mathrm{a}$ ). Analysis of the amplitude in the last 10 minutes of the experiment con- (a) MTT: Hippocampus

(b) CTT: Hippocampus
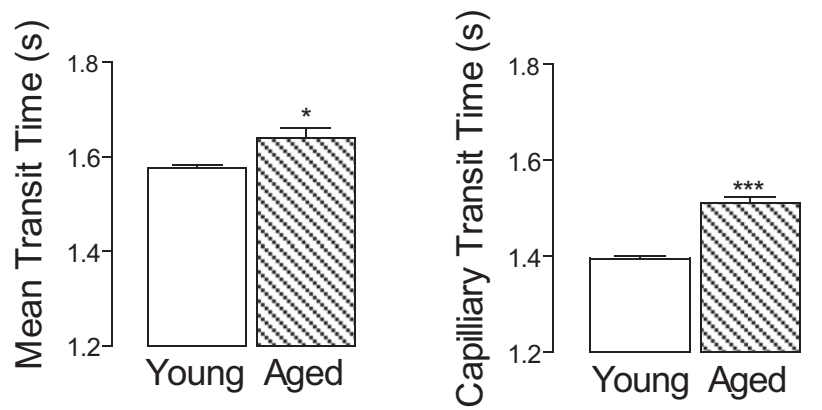

(c) MTT: Cortex

(d) CTT: Cortex
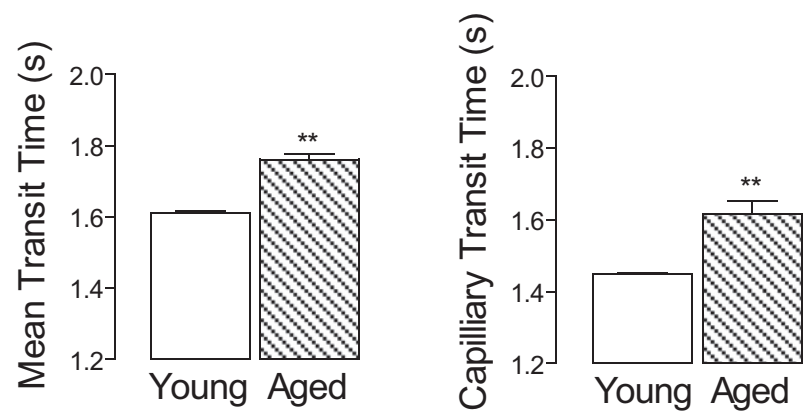

Fig. 1. Mean transit time (MTT) (a, c) and capillary transit time (CTT) (b, d) were significantly increased in the hippocampus (a, b) and cortex (c, d) of aged, compared with young, rats (* $p<0.05$; ** $p<0.01$; *** $p<$ 0.001; Student $t$ test for independent means; $n=8$ ).

firmed that there was a significant age-related deficit in synaptic plasticity (*** $p<0.001$; ANOVA; Fig. 2b).

Several factors have been associated with decreased LTP, 1 of which is glial activation which is considered to significantly contribute to the age-related inflammatory changes which have been consistently reported (Lynch, 2010). Here we assessed expression of CD11b mRNA, $\mathrm{CD} 11 \mathrm{~b}$ immunoreactivity, and the number of $\mathrm{CD} 11 \mathrm{~b}^{+}$ $\mathrm{OX}^{+}$cells prepared from whole brain of young and aged rats using FCM. CD11b mRNA was significantly higher, and immunoreactivity for CD11b was markedly greater in hippocampal (Fig. 3a and b) and cortical (Fig. 3c and d) tissue prepared from aged, compared with young, rats (* $p<0.05 ; * * * p<0.001$; Student $t$ test for independent means). The number of $\mathrm{CD} 11 \mathrm{~b}^{+} \mathrm{OX}^{+}$cells, which is indicative of microglial activation, was also significantly greater in dissociated cells prepared from the whole brain of aged, compared with young, rats $(* * * p<0.001$; Student $t$ test for independent means; Fig. 1e). The changes in CD11b mRNA and CD11b immunoreactivity were mirrored by changes in CD68; CD68 mRNA was significantly greater in tissue prepared from hippocampus (Fig. 1f) and cortex (Fig. $1 \mathrm{~h})$ of aged, compared with young rats $(* p<0.05$; ** $p<$ 0.01 ; Student $t$ test for independent means) and an agerelated increase in CD68 immunoreactivity was similarly observed in hippocampus (Fig. 1g) and cortex (Fig. 1i). 
(a)

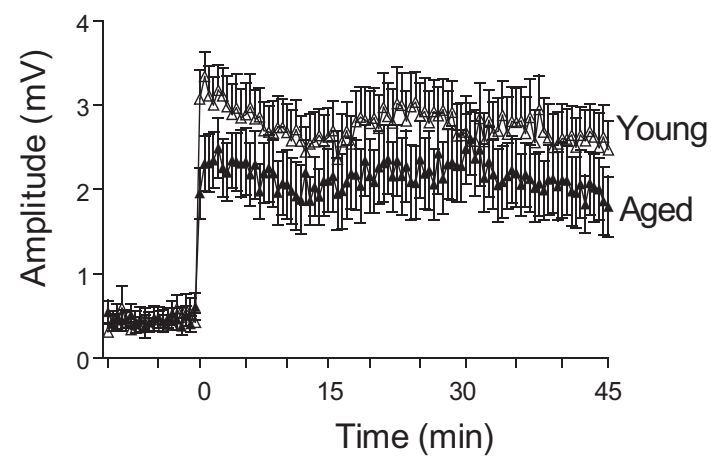

(b)

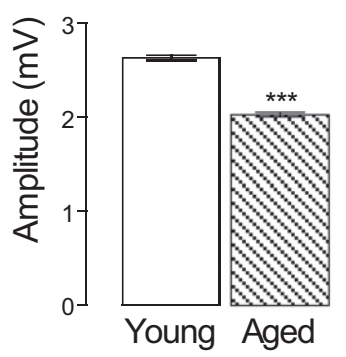

Fig. 2. Long-term potentiation (LTP), as assessed by the mean change in population spike amplitude, was significantly attenuated in dentate gyrus of aged, compared with young, rats ( $p<0.001$; analysis of variance [ANOVA]; a) and the mean change in the last 10 minutes of the experiment also revealed a significant age-related change (*** $p<0.001$; Student $t$ test for independent means; $n=14 ; \mathrm{b})$.

There was a significant correlation between LTP and hippocampal expression of CD11b mRNA $(r=-0.77, p<$ 0.01, $n=11$; Fig. 3 j) and CD68 mRNA $(r=-0.75, p<$ $0.01, n=11$; Fig. $3 \mathrm{k}$ ).

We used MSME to assess T2 relaxation time, and comparison of the sample maps from a young and aged rat indicated a generalized decrease throughout the brain with age (Fig. 4a). Analysis of the mean data indicated that T2 relaxation time was significantly decreased in cortex and hippocampus of aged, compared with young, rats $(* * p<$ 0.01 ; Student $t$ test for independent means; Fig. $4 \mathrm{~b}$ and c). A similar, though quantitatively different, age-related change was observed when T2 was assessed by the FISP method; in this case the mean values ( \pm standard error of the mean $[\mathrm{SEM}])$ in hippocampus were $69.85 \pm 1.02$ and $63.08 \pm 2.14$ in young and aged animals respectively $(p<$ 0.05 ) and the mean values in the cortex were $74.37 \pm 0.78$ and $66.40 \pm 1.03$ in young and aged animals respectively $(p<0.001)$. There was a significant negative correlation between CTT and T2 relaxation in both hippocampus $(r=$ $-0.51, p<0.01$; Fig. 4d) and cortex $(r=-0.53, p<0.05$; Fig. 4e). Furthermore, T2 relaxation in the hippocampus significantly correlated with LTP $(r=0.78, p<0.01, n=$ 11; Fig. 4f) and negatively correlated with hippocampal CD11b $(r=-0.72, p<0.01, n=11$; Fig. $4 \mathrm{~g})$ and CD68 $(r=-0.82, p<0.01, n=11$; Fig. 4h) mRNA expression. The data presented were obtained from isoflurane-anesthetized rats and similar data were obtained from propofolanesthetized rats (data not shown).

In contrast to the change in $\mathrm{T} 2$ relaxation time, analysis of T1 relaxation time using RARE revealed no significant age-related changes in either hippocampus (Fig. 5a) or cortex (Fig. 5c). However previous data indicated that $\mathrm{T} 1$ relaxation time was higher in 20-month-old rats than in younger animals (Cowley et al., 2010) and it has been reported by others that $\mathrm{T} 1$ relaxation time peaks at middle age (Aquino et al., 2009). To further evaluate this, data from several cohorts of rats were pooled and the findings support the contention that $\mathrm{T} 1$ relaxation time is age-dependent in hippocampus (Fig. 5b) and cortex (Fig. 5d).

Contrast-enhanced imaging was performed under propofol anesthesia because it has been reported that isoflurane opens the BBB (Tétrault et al., 2008). The periventricular region, hippocampus, and cortex of young and aged rats were analyzed for pre- versus postcontrast signal intensity. The images presented (Fig. 6a) are exemplary and suggest that signal intensity was significantly higher in the brain of an aged rat compared with a young rat 2 minutes after injection of contrast agent. Analysis of the periventricular region (Fig. 6b) indicated that there was a marked agerelated and time-associated difference in diffusion and clearance of the contrast agent $(p<0.001$; ANOVA; Fig. $6 \mathrm{~b})$. The periventricular region sampled comprises the ventricle (and therefore cerebrospinal fluid [CSF]) and also tissue adjacent to the ventricle which did not contain any major blood vessels (established by making reference to the ASL scans). The presence of the CSF explains the greater impact of the contrast agent on the signal in this, compared with hippocampal and cortical, ROIs. The data may be indicative of an age-related increase in permeability in the blood-CSF barrier (time $\times$ age interaction, $p<0.05$; repeated measures 2-way ANOVA). A significant age-related decrease in clearance of the contrast agent from the hippocampus was observed ( $p<0.001$; ANOVA; Fig. $6 c)$ and the interaction between time and age was significant $(p<$ 0.05; repeated measures 2-way ANOVA). It should be noted that an age-related difference in signal enhancement was evident about 2 minutes following intravenous administration of the contrast agent in the periventricular area compared with about 7 minutes after administration in the hippocampus. The delay in contrast enhancement in the hippocampal tissue probably reflects the slower diffusion of contrast agent deeper into the tissue, which is particularly evident in aged animals. A similar gradual increase in signal intensity has also been reported following temporary breakdown of the BBB by claudin 5 knockdown (Campbell et al., 
(a) Hipp

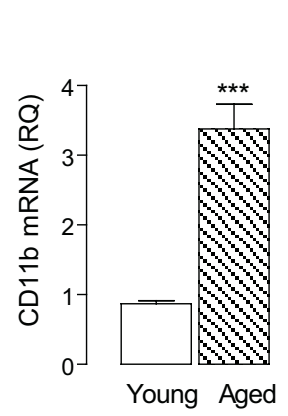

(b) Hipp
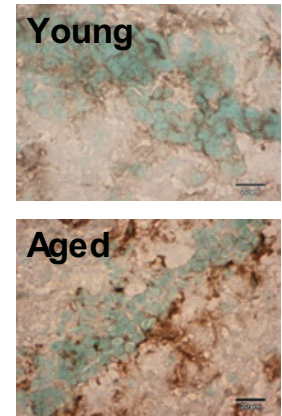

(c) Cortex

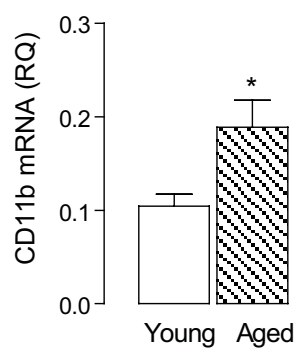

(d) Cortex

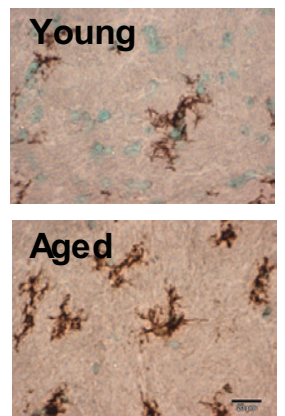

(e) Whole brain

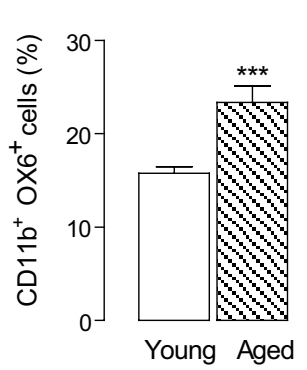

(f) Hipp

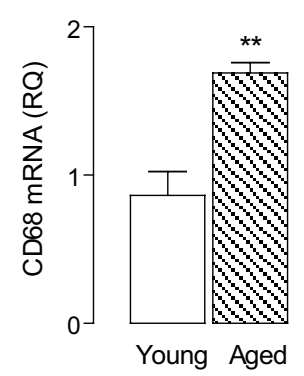

(g) Hipp

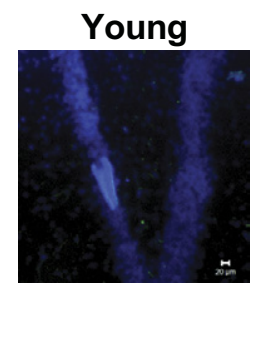

(j)

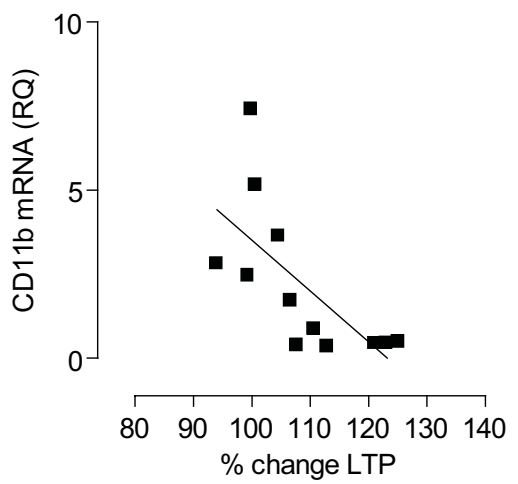

(h) Cortex

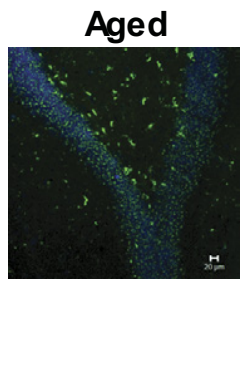

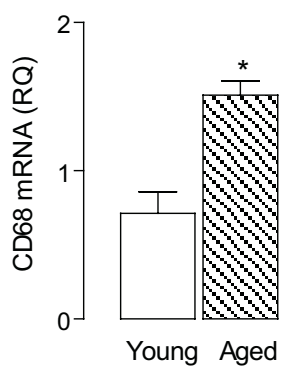

(k) (i) Cortex

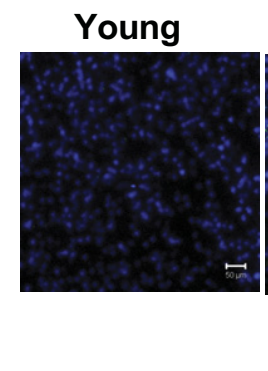

Aged
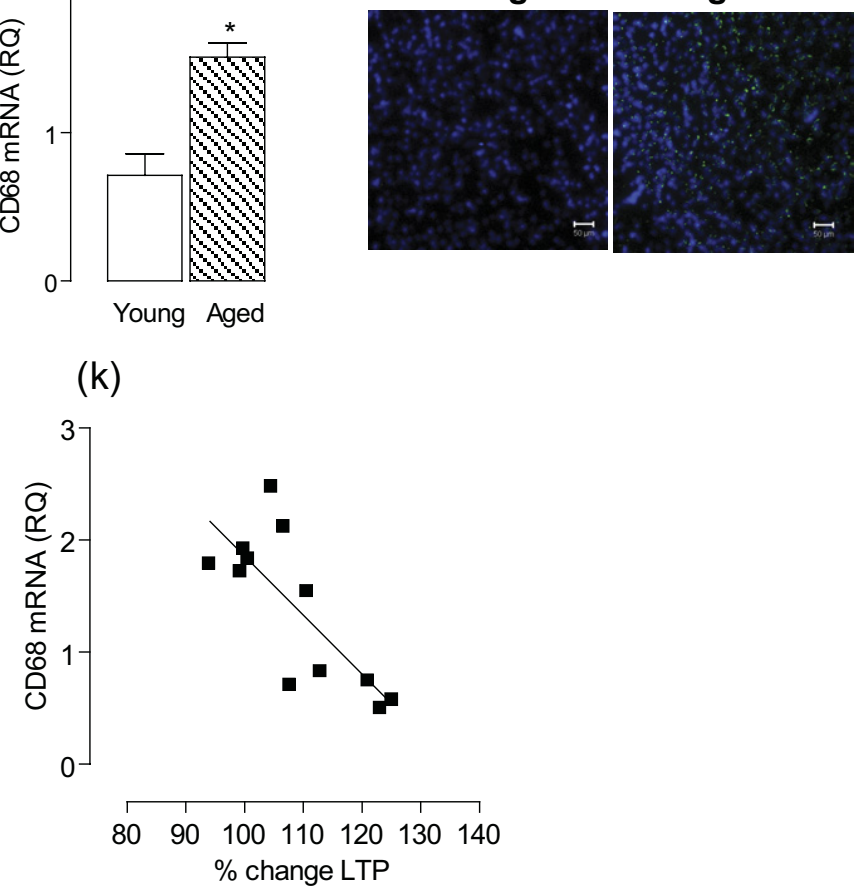

Fig. 3. CD11b messenger Ribonucleic Acid (mRNA) was significantly increased in hippocampal (a) and cortical (c) tissue prepared from aged, compared with young, rats (*p<0.05; *** $p<0.001$; Student $t$ test for independent means; $n=6$ ). CD11b immunoreactivity in hippocampal (b) and cortical (d) tissue was also markedly increased with age. (e) The number of CD11b ${ }^{+}$cells which also stained positively for OX6 was significantly increased in cells prepared from cortical tissue obtained from aged, compared with young, rats (*** $p<0.001$; Student $t$ test for independent means; $n=14$ ). CD68 mRNA was significantly increased in hippocampal (f) and cortical (h) tissue prepared from aged, compared with young, rats $(* p<0.05 ; * * p<0.01 ;$ Student $t$ test for independent means; $n=6$ ) and similarly CD68 immunoreactivity in hippocampal (g) and cortical (i) tissue were also markedly increased with age. There was a significant negative correlation between LTP and (j) hippocampal expression of CD11b mRNA $(r=-0.77 ; p<0.01 ; n=11)$ and $(\mathrm{k})$ CD68 mRNA $(r=-0.75 ; p<0.01 ; n=11)$.

2008); poor junctional localization of claudin-5 with loss of integrity of the BBB in the hippocampus have previously been reported in female middle-aged rats (Bake et al., 2009). In contrast to the change in hippocampus, there was no significant age-related change in signal intensity in the cortex (Fig. 6d). The possibility exists that changes in hippocampal volume may impact on measurement of BBB permeability. In this study, there was no evidence of a change in hippocampal volume $(4.18 \pm 0.34 \%$ and $3.93 \pm$
$0.49 \%$ of intracranial volume in young and aged rats respectively; $p>0.1$ ) although a decrease in cortical thickness at the level of the dorsal hippocampus (bregma -3.6 $\mathrm{mm})$ was observed $(1.78 \pm 0.13 \mathrm{~mm}$ and $1.45 \pm 0.24 \mathrm{~mm}$ in young and aged rats respectively; $p<0.01$; Student $t$ test for independent means).

Although the blood-brain barrier is considered primarily to be a barrier to the movement of solutes and molecules, evidence suggests that an increase in its permeability may 
(a)

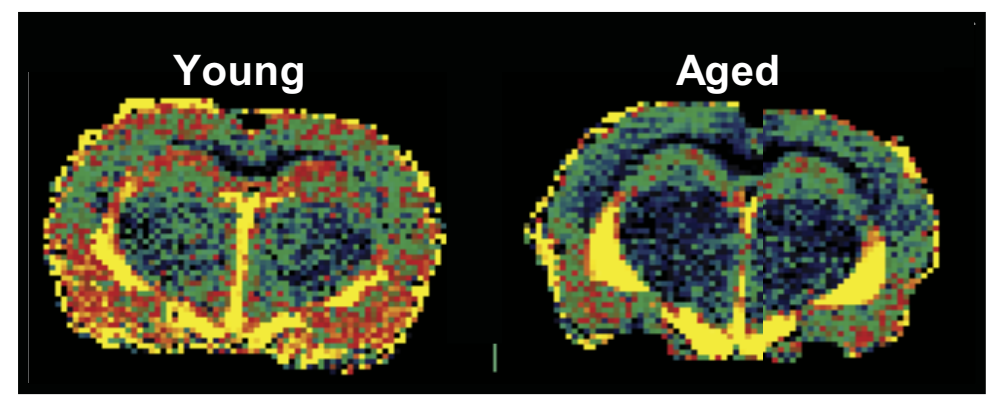

(b) Hippocampus

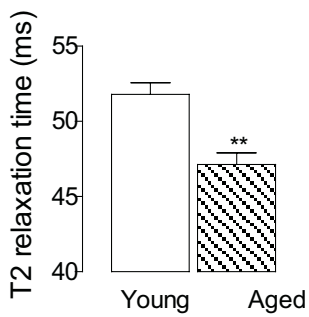

(d) Hippocampus

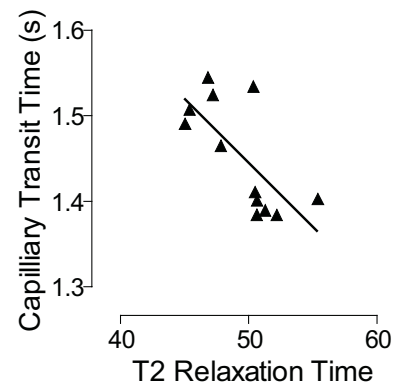

(f)

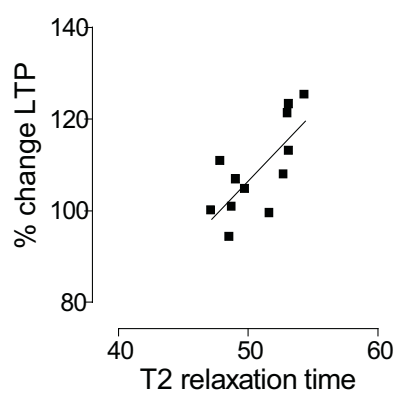

(c) Cortex

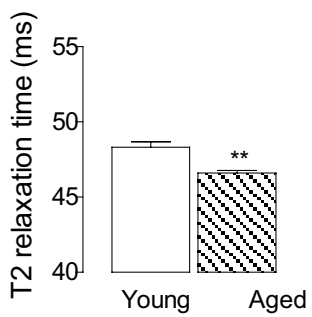

(e) Cortex

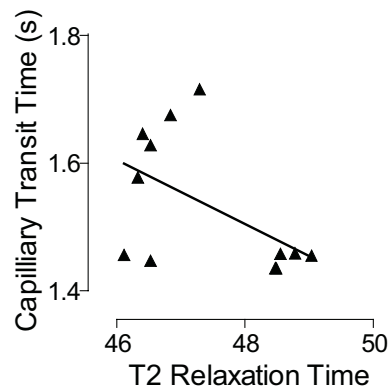

(h)

(g)

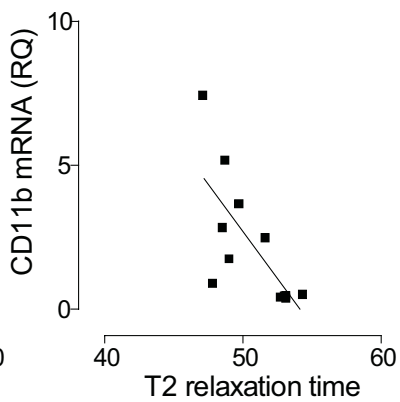

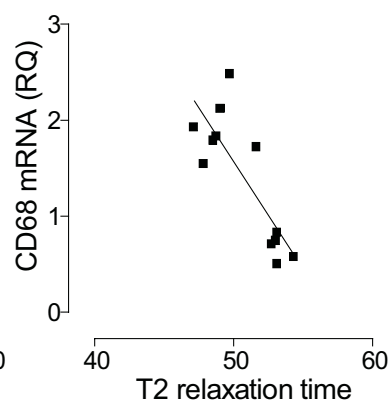

Fig. 4. T2 relaxation time was decreased in the brains of aged, compared with young, rats (a) and analysis of the data in hippocampal (b) and cortical (c) tissue revealed a significant age-related decrease (** $p<0.01$; Student $t$ test for independent means; $n=6$ ). There was a significant correlation between capillary transit time (CTT) and T2 relaxation in hippocampus $(r=0.51 ; n=12 ; p<0.01 ; \mathrm{d})$ and cortex $(r=0.53 ; n=12 ; p<0.05 ; \mathrm{e})$. T2 relaxation in the hippocampus significantly correlated with (f) long-term potentiation (LTP) $(r=0.78 ; p<0.01 ; n=11)$ and (g) hippocampal CD11b ( $r=-0.72$; $p<0.01 ; n=11)$ and (h) CD68 $(r=-0.82 ; p<0.01 ; n=11)$ mRNA expression.

also permit infiltration of cells (Popescu et al., 2009), although this mainly occurs under the influence of chemotactic molecules. Here we show that expression of IP-10 and MCP-1 which play a significant role in chemotaxis of peripheral cells (Babcock et al., 2003) were increased in brain tissue prepared from aged, compared with young, rats (* $p<0.05$; *** $p<0.001$; Student $t$ test for independent means; Fig. 7a and b). These changes were accompanied by an increase in the number of $\mathrm{CD} 11 \mathrm{~b}^{+} \mathrm{CD} 45^{+}$cells (which are probably macrophages [Carson et al., 1998]) in whole 
(a) Hipp

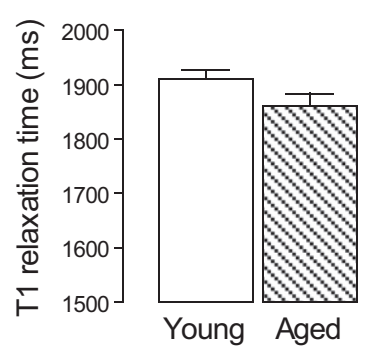

(c) Cortex
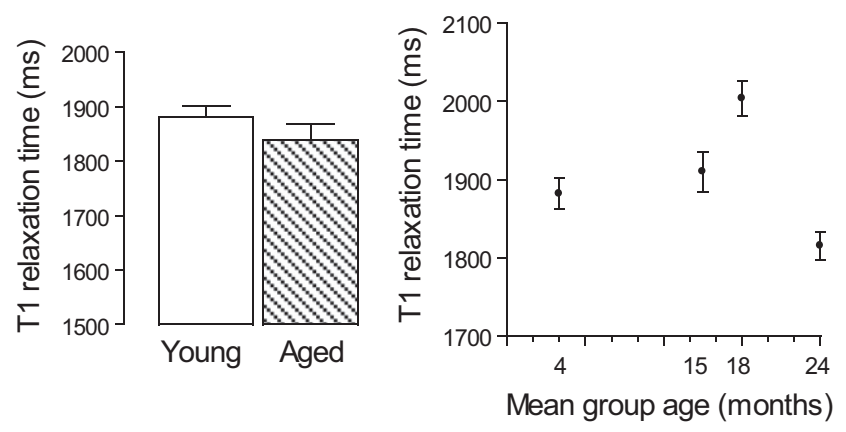

Fig. 5. T1 relaxation time was similar in hippocampus (a) and cortex (c) of aged and young rats. However, when data from other studies in which rats of different ages were assessed, it was evident that $\mathrm{T} 1$ relaxation time was increased in 18-month-old compared with 24-month-old rats in hippocampus and cortex ( $p<0.001$; analysis of variance [ANOVA]; $n=12 ; \mathrm{b}$ and d).

brain; ** $p<0.01$; Student $t$ test for independent means; Fig 7c.

\section{Discussion}

A key challenge in neuroscience is to understand the mechanisms underlying the age-related neuroinflammatory changes which contribute to the characteristic deficit in neuronal function. The ability to noninvasively detect agerelated changes in vivo to which neuroinflammation may be contributing, and to link these changes to well-established ex vivo markers of neuroinflammation has the potential to provide valuable insights into the mechanisms behind agerelated cognitive decline. In this study, we set out to evaluate whether the increase in microglial activation and the associated deficit in LTP in aged animals was linked with changes in perfusion or BBB permeability as assessed by MRI. In addition, we also investigated $\mathrm{T} 1$ and $\mathrm{T} 2$ relaxation times because previous findings suggested that these parameters are altered in several neuroinflammatory conditions and changes in these parameters may reflect changes in glial activation.

The evidence indicates that MTT and CTT were increased in hippocampus and cortex of aged, compared with young, rats and that these changes were accompanied by increased BBB permeability. An increase in the number of $\mathrm{CD}_{11} \mathrm{~b}^{+} \mathrm{CD} 45^{+}$cells were observed in the brain of aged rats and this was associated with upregulation of MCP-1 and IP-10. Interestingly the data show that there was an age-related decrease in T2 relaxation time and this, as previously reported, was accompanied by evidence of microglial activation (Falangola et al., 2005; Justicia et al., 2008; Teipel et al., 2011). Overall the evidence suggests that multiple changes occur in the brain with age which might contribute to the deficit in LTP observed here and elsewhere.

The data demonstrate an age-related increase in both MTT and CTT in hippocampus and cortex, although similar changes were observed in most areas of the brain and also in a whole brain slice (data not shown). This suggests a generalized decrease in cerebral perfusion with age and concurs with the observations that cerebral blood flow is decreased in rat and humans with age (Mitschelen et al., 2009; van Es et al., 2010) and that cerebral blood flow changes in hippocampal subregions are inversely correlated with age in nonhuman primates and rats (Small et al., 2004). The increases in MTT and CTT are probably due to a combination of decreased blood flow and altered perfusion coefficient of the tissue (Kelly et al., 2009). MTT has been shown to correlate with accumulation of lactate following stroke suggesting that it may provide a marker of ischemia (Cvoro et al., 2009) and, in this context, it is interesting that there is evidence of oxidative changes in the brain of aged rats (Kelly et al., 2011; O'Donnell et al., 2000). These changes cannot be attributed to any age-related difference in hippocampal volume because, although a decrease in cortical thickness was observed, we found no evidence of any difference in hippocampal volume in aged, compared with young, rats. However, analysis using a 9.4 Tesla magnet revealed an age-dependent decrease in hippocampal volume of Fisher $344 \times$ Brown Norway hybrid rats (Driscoll et al., 2006), suggesting that there may be strain differences between these rats and the Wistar rats used here, or that the field strength used in this study may not be strong enough to highlight subtle volumetric differences.

Chronic hypoperfusion has been associated with a decrease in cognitive function and neuronal plasticity, specifically LTP (Lin et al., 2010) and similar changes were observed following ischemia which is also associated with decreased perfusion ( $\mathrm{Li}$ et al., 2010). Here we show that the age-related decrease in MTT and CTT in the hippocampus is associated with a decrease in LTP, which is reported here and elsewhere (Cowley et al., 2010; Kelly et al., 2010), indicating that a relatively modest decrease in cerebral perfusion may impact on synaptic function.

Among the several factors which accompany, and probably contribute to, the age-related decrease in synaptic plasticity is microglial activation (Lynch, 2010), probably because these cells are the main source of inflammatory 
(a)

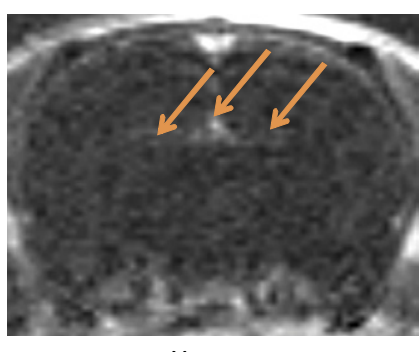

Young

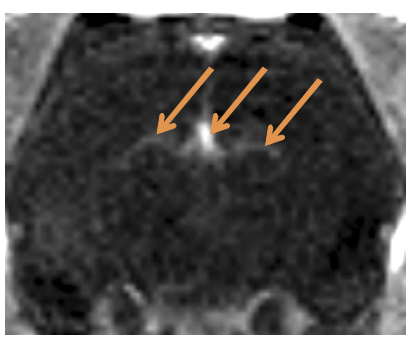

Aged (b) Periventricular region

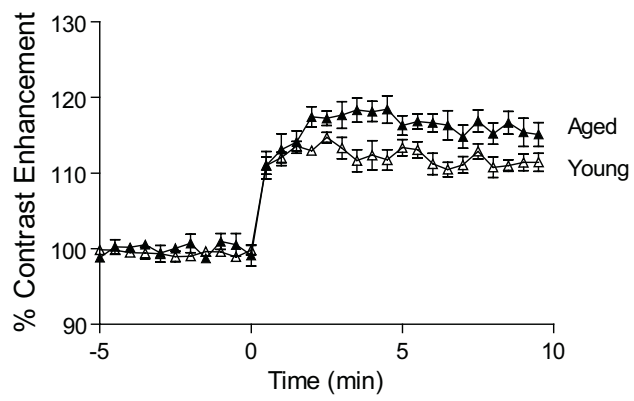

(c) Hippocampus

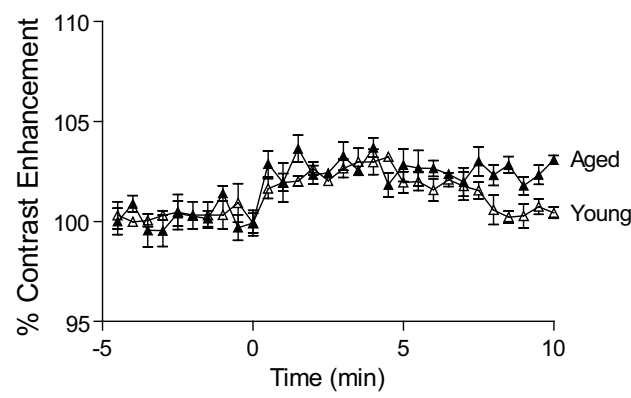

(d) Cortex

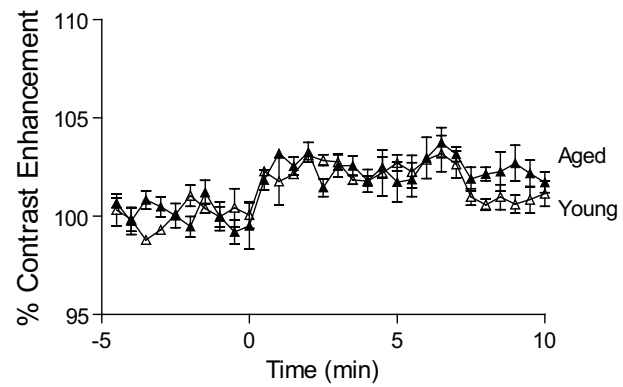

Fig. 6. There was an increase in postcontrast signal intensity (indicative of blood-brain barrier [BBB] disruption) in the periventricular area (a and b; $p<$ 0.001; analysis of variance [ANOVA]; $n=8$ ) and hippocampus (c; $p<0.001$; ANOVA; $n=8)$ but not cortex (d) of aged, compared with young, rats.

cytokines in the brain. In this study, CD11b mRNA and CD11b immunoreactivity were increased in hippocampal tissue prepared from aged rats and, in addition, the number of CD11b-positive cells which also stained positively for OX6 was increased in tissue prepared from aged, compared with young rats. These changes were mirrored by changes in CD68 mRNA and immunoreactivity. Moreover, the increased expression of CD11b and CD68 mRNA in hippocampus inversely correlated with the decrease in LTP. Overall, the data are indicative of microglial activation and therefore support previous observations which suggested that the age-related deficit in LTP is coupled with microglial activation, probably because the production and release of inflammatory mediators is increased from activated cells.
This idea is strengthened by the finding that agents that decrease microglial activation in aged animals improve their ability to sustain LTP (Lynch, 2010). In addition to the changes in hippocampus, both CD11b and CD68 were upregulated in cortical tissue prepared from aged, compared with young, rats. One possibility is that these changes are triggered by the reduced blood perfusion because microglial activation can be increased by oxidative changes (Nolan et al., 2005).

The potential application of inversion-recovery steadystate precession imaging (the FISP protocol) to MR relaxometry is relatively new: Schmitt et al. (2004) first described a novel procedure to extract $\mathrm{T} 1, \mathrm{~T} 2$, and relative spin density from the signal time course of the FISP se- (a)

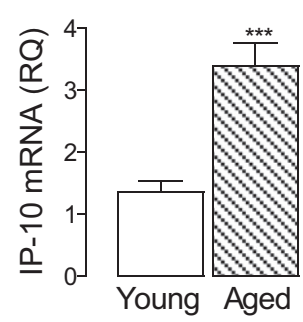

(b)

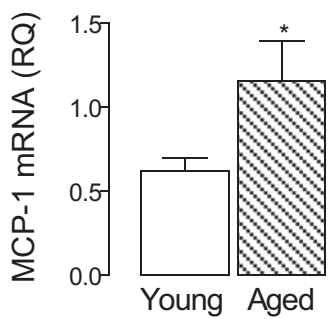

(c)

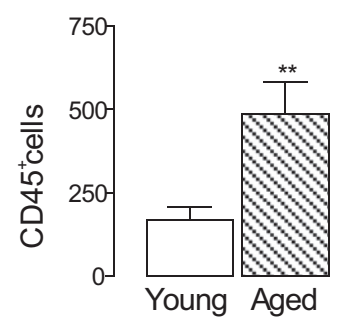

Fig. 7. Mean IP-10 mRNA and MCP-1 mRNA were significantly increased in hippocampal tissue prepared from aged, compared with young, rats (a and b; $* p<0.05 ; * * *<<0.001$; Student $t$ test for independent means; $n=14$ ). There was a significant increase in the number of CD11 ${ }^{+} \mathrm{CD} 45^{+}$cells in cortex of aged, compared with young, rats (c;** $p<0.01$; Student $t$ test for independent means; $n=8$ ). 
quence. The main benefit, compared with other techniques, is the increased speed of data acquisition; however, the multispin-echo technique is still the gold standard for T2 map calculation where rapid imaging is not required (Schmitt et al., 2004). There are a number of potential sources of error in the FISP calculation: first, neither blood and CSF flow into the imaging slice nor diffusion effects are considered, and no corrections for these are made (Schmitt et al., 2004). Second, this technique was validated in phantoms and human subjects at a field strength of 1.5 Tesla, and absolute values obtained at 7 Tesla in rat brain must be interpreted with caution in the absence of validation studies. Additionally, partial volume effects due to CSF (which has a longer T2) may confound T2 relaxometry. The MSME sequence incorporates an additional inversion pulse to suppress signal from CSF in order to minimize this effect. The FISP method does not allow for a similar compensatory mechanism, and may therefore overestimate T2 in voxels adjacent to ventricles. Finally, FISP is highly sensitive to off-resonance radio waves, resulting in banding artifacts which confound image analysis (Schmitt et al., 2004). Datasets used in this study were visually inspected for banding artifacts and only data without such effects were included in the analysis. In this study we found that, while absolute values obtained by the 2 imaging techniques were not comparable (FISP-derived values for T2 relaxation time were higher), relative changes between groups were comparable. The most likely explanation for this is a systematic overestimation of $\mathrm{T} 2$ by FISP.

We report here that $\mathrm{T} 2$ relaxation time was markedly decreased in hippocampus and cortex of rats aged 20-26 months old, compared with young rats. However, we reported previously that $\mathrm{T} 2$ relaxation time was unchanged in 20-22-month-old rats (Cowley et al., 2010) suggesting a progressive change in $\mathrm{T} 2$ with age. Interestingly, an agerelated decrease in $\mathrm{T} 2$ relaxation time has been reported in human subjects (Siemonsen et al., 2008), although an earlier study in which younger subjects were assessed, suggested there was no age-related change (Breger et al., 1991) which also indicates that changes are age-dependent. Here the change in T2 relaxation time accompanies microglial activation and inversely correlated with mRNA expression of CD11b and CD68 in hippocampus; an inverse relationship between decreased T2 relaxation time and microglial activation has been described previously at least in animal models of ischemic stroke (Justicia et al., 2008) and Alzheimer's disease (Falangola et al., 2005; Teipel et al., 2011). Moreover, hippocampal T2 relaxation time correlated with LTP indicating interplay between T2 relaxation times, microglial activation and the ability to sustain LTP.

T2 relaxation time is affected by several factors; decreased T2 relaxations times have been associated with deposition of amyloid $\beta$ and deposition of iron (Bartzokis et al., 2000; Helpern et al., 2004) and with cell shrinkage (O'Shea et al., 2000); whereas increased T2 relaxation time is associated with edema (Fabene et al., 2003). It has been suggested that reductions in $\mathrm{T} 2$ may also result from reduced perfusion and decreased blood oxygenation (Grohn et al., 2000) and, in the present study, the evidence suggests a significant relationship between $\mathrm{CTT}$ and $\mathrm{T} 2$ relaxation time which broadly supports this proposal.

Astrocytosis, which occurs with age and following acute ischemia, has been coupled with increased $\mathrm{T} 1$ relaxation times (Cowley et al., 2010; Sibson et al., 2008) although increased T1 values are also associated with axonal loss, at least in white matter (van Walderveen et al., 1998), edema (Barnes and McDonald, 1988), and the lesions which characterize multiple sclerosis (Parry et al., 2002). The evidence presented here indicates that the relationship between $\mathrm{T} 1$ and age is not straightforward, with evidence of little change in older age and an increase in middle age. Interestingly, these findings reflect a previous observation which demonstrated that, in humans, gray matter $\mathrm{T} 1$ relaxation times were highest in middle age, with both younger and older subjects showing lower values (Aquino et al., 2009).

One significant finding in the present study is that BBB permeability was increased with age. These data are in accord with the findings of others that report age-related alterations in BBB permeability in the senescent mouse (Pelegrí et al., 2007) and human (Pakulski et al., 2000). Significant changes were observed in hippocampus but not the cortex and this concurs with the observation that the $\mathrm{BBB}$ in the hippocampal area may be particularly vulnerable in the senescence-accelerated mouse, SAMP8 (Pelegrí et al., 2007). Evidence from this laboratory (Murray et al., unpublished), suggests that the BBB of aged rats is more permeable to sodium fluorescein than that of young rats in several areas including the hippocampus. The BBB plays a key role in modulating entry of solutes and ions into the central nervous system (CNS) whereas migration of cells appears to be controlled to a significant extent by expression of chemokines and adhesion molecules. Despite this, infiltration of circulating cells has been shown to occur when BBB permeability is increased. Thus $\mathrm{T}$ cell infiltration has been found in CNS tissues of patients with Parkinson's disease (Stone et al., 2009) and Alzheimer's disease (Schindowski et al., 2007; Togo et al., 2002) and infiltration of cells has also been reported following ischemic insult and with age (Popescu et al., 2009) and bacterial and viral infections (Stamatovic et al., 2008). In this study, increased BBB permeability was associated with increased expression of IP-10 and MCP-1. Infiltration of leukocytes is dependent on chemotaxis and expression of both IP-10 and MCP-1 have been identified as important; a role for MCP-1 has also been described in initiating infiltration of macrophages into the brain (Babcock et al., 2003). Therefore the infiltration of $\mathrm{CD}_{11} \mathrm{~b}^{+} \mathrm{CD} 45^{+}$cells may be a consequence of the change in $\mathrm{BBB}$ permeability but it is also possible that the increased expression of IP-10 and MCP-1 increase chemotaxis. 
Several factors contribute to the deterioration of synaptic plasticity with age and 1 of these factors appears to be a heightened level of activation of microglia, which may reflect impairment in the homeostatic ability of these cells with age, or an increase in responsiveness to modulatory molecules. The evidence presented here indicates that the age-related decrease in tissue perfusion, together with the increase in BBB permeability may alter the microenvironment in the brain; this, combined with the proposed agerelated compromised homeostatic capability of microglia, may be a significant factor in maintaining the neuroinflammatory changes which have been described in the aged brain and which exert a negative impact on synaptic function.

\section{Disclosure statement}

C.W.B., T.R.C., J.O., and N.M. were funded by GlaxoSmithKline. Otherwise there are no conflicts of interest.

All experiments were performed under a license issued by the Department of Health (Ireland) and in accordance with the guidelines laid down by the Trinity College ethical committee.

\section{Acknowledgements}

This work was supported by grants from GlaxoSmithKline and the Industrial Development Agency, Ireland, Health Research Board (Ireland) and Science Foundation, Ireland.

\section{References}

Anderson, V.M., Fox, N.C., Miller, D.H., 2006. Magnetic resonance imaging measures of brain atrophy in multiple sclerosis. J. Magn. Reson. Imaging 23, 605-618.

Aquino, D., Bizzi, A., Grisoli, M., Garavaglia, B., Bruzzone, M.G., Nardocci, N., Savoiardo, M., Chiapparini, L., 2009. Age-related iron deposition in the basal ganglia: quantitative analysis in healthy subjects. Radiology 252, 165-172.

Babcock, A.A., Kuziel, W.A., Rivest, S., Owens, T., 2003. Chemokine expression by glial cells directs leukocytes to sites of axonal injury in the CNS. J. Neurosci. 23, 7922-7930.

Bake, S., Friedman, J.A., Sohrabji, F., 2009. Reproductive age-related changes in the blood brain barrier: expression of $\mathrm{IgG}$ and tight junction proteins. Microvasc. Res. 78, 413-424.

Barnes, D., McDonald, W.I., 1988. A magnetic resonance imaging study of experimental cerebral edema and its response to dexamethasone. Magn. Reson. Med. 7, 125-131.

Bartzokis, G., Sultzer, D., Cummings, J., Holt, L.E., Hance, D.B., Henderson, V.W., Mintz, J., 2000. In vivo evaluation of brain iron in Alzheimer disease using magnetic resonance imaging. Arch. Gen. Psychiatry $57,47-53$.

Breger, R.K., Yetkin, F.Z., Fischer, M.E., Papke, R.A., Haughton, V.M., Rimm, A.A., 1991. T1 and T2 in the cerebrum: correlation with age, gender, and demographic factors. Radiology 181, 545-547.

Campbell, M., Kiang, A.S., Kenna, P.F., Kerskens, C., Blau, C., O’Dwyer, L., Tivnan, A., Kelly, J.A., Brankin, B., Farrar, G.J., Humphries, P., 2008. RNAi-mediated reversible opening of the blood-brain barrier. J. Gene Med. 10, 930-947.
Carson, M.J., Reilly, C.R., Sutcliffe, J.G., Lo, D., 1998. Mature microglia resemble immature antigen-presenting cells. Glia 22, 72-85.

Cowley, T.R., O'Sullivan, J., Blau, C., Deighan, B.F., Jones, R., Kerskens, C., Richardson, J.C., Virley, D., Upton, N., Lynch, M.A., 2010. Rosiglitazone attenuates the age-related changes in astrocytosis and the deficit in LTP. Neurobiol. Aging. doi: 10.1016/j.neurobiolaging. 2010.02.002.

Cvoro, V., Wardlaw, J.M., Marshall, I., Armitage, P.A., Rivers, C.S., Bastin, M.E., Carpenter, T.K., Wartolowska, K., Farrall, A.J., Dennis, M.S., 2009. Associations between diffusion and perfusion parameters, $\mathrm{N}$-acetyl aspartate, and lactate in acute ischemic stroke. Stroke 40, 767-772.

Dixon, W.T., Du, L.N., Faul, D.D., Gado, M., Rossnick, S., 1986. Projection angiograms of blood labeled by adiabatic fast passage. Magn. Reson. Med. 3, 454-462.

Downer, E.J., Cowley, T.R., Lyons, A., Mills, K.H., Berezin, V., Bock, E., Lynch, M.A., 2010. A novel anti-inflammatory role of NCAM-derived mimetic peptide, FGL. Neurobiol. Aging 31, 118-128.

Driscoll, I., Howard, S.R., Stone, J.C., Monfils, M.H., Tomanek, B., Brooks, W.M., Sutherland, R.J., 2006. The aging hippocampus: a multi-level analysis in the rat. Neuroscience 139, 1173-1185.

Fabene, P.F., Marzola, P., Sbarbati, A., Bentivoglio, M., 2003. Magnetic resonance imaging of changes elicited by status epilepticus in the rat brain: diffusion-weighted and T2-weighted images, regional blood volume maps, and direct correlation with tissue and cell damage. Neuroimage 18, 375-389.

Falangola, M.F., Lee, S.P., Nixon, R.A., Duff, K., Helpern, J.A., 2005. Histological co-localization of iron in Abeta plaques of PS/APP transgenic mice. Neurochem. Res. 30, 201-205.

Griffin, K.M., Blau, C.W., Kelly, M.E., O’Herlihy, C., O'Connell, P.R., Jones, J.F., Kerskens, C.M., 2010. Propofol allows precise quantitative arterial spin labelling functional magnetic resonance imaging in the rat. Neuroimage 51, 1395-1404.

Grohn, O.H., Kettunen, M.I., Penttonen, M., Oja, J.M., van Zijl, P.C., Kauppinen, R.A., 2000. Graded reduction of cerebral blood flow in rat as detected by the nuclear magnetic resonance relaxation time T2: a theoretical and experimental approach. J. Cereb. Blood Flow Metab. 20, 316-326.

Helpern, J.A., Lee, S.P., Falangola, M.F., Dyakin, V.V., Bogart, A., Ardekani, B., Duff, K., Branch, C., Wisniewski, T., de Leon, M.J., Wolf, O., O'Shea, J., Nixon, R.A., 2004. MRI assessment of neuropathology in a transgenic mouse model of Alzheimer's disease. Magn. Reson. Med. 51, 794-798.

Justicia, C., Ramos-Cabrer, P., Hoehn, M., 2008. MRI detection of secondary damage after stroke: chronic iron accumulation in the thalamus of the rat brain. Stroke 39, 1541-1547.

Kelly, L., Grehan, B., Chiesa, A.D., O'Mara, S.M., Downer, E., Sahyoun, G., Massey, K.A., Nicolaou, A., Lynch, M.A., 2011. The polyunsaturated fatty acids, EPA and DPA exert a protective effect in the hippocampus of the aged rat. Neurobiol. Aging 32, 2318.e1-2318.e15.

Kelly, M.E., Blau, C.W., Griffin, K.M., Gobbo, O.L., Jones, J.F., Kerskens, C.M., 2010. Quantitative functional magnetic resonance imaging of brain activity using bolus-tracking arterial spin labeling. J. Cereb. Blood Flow Metab. 30, 913-922.

Kelly, M.E., Blau, C.W., Kerskens, C.M., 2009. Bolus-tracking arterial spin labelling: theoretical and experimental results. Phys. Med. Biol. 54, 1235-1251.

Kerskens, C.M., Hoehn-Berlage, M., Schmitz, B., Busch, E., Bock, C., Gyngell, M.L., Hossmann, K.A., 1996. Ultrafast perfusion-weighted MRI of functional brain activation in rats during forepaw stimulation: comparison with T2 -weighted MRI. NMR Biomed. 9, 20-23.

Li, S., He, Z., Guo, L., Huang, L., Wang, J., He, W., 2010. Behavioral alterations associated with a down regulation of HCN1 mRNA in hippocampal cornus ammon 1 region and neocortex after chronic incomplete global cerebral ischemia in rats. Neuroscience 165, 654661. 
Lin, Q., Hai, J., Yao, L.Y., Lu, Y., 2010. Neuroprotective effects of NSTyr on cognitive function and neuronal plasticity in rats of chronic cerebral hypoperfusion. Brain Res. 1325, 183-190.

Loane, D.J., Deighan, B.F., Clarke, R.M., Griffin, R.J., Lynch, A.M., Lynch, M.A., 2009. Interleukin-4 mediates the neuroprotective effects of rosiglitazone in the aged brain. Neurobiol. Aging 30, 920-931.

Lynch, M.A., 2010. Age-related neuroinflammatory changes negatively impact on neuronal function. Front. Aging Neurosci. 1, 6.

McQuillan, K., Lynch, M.A., Mills, K.H., 2010. Activation of mixed glia by Abeta-specific Th1 and Th17 cells and its regulation by Th2 cells. Brain Behav. Immun. 24, 598-607.

Mitschelen, M., Garteiser, P., Carnes, B.A., Farley, J.A., Doblas, S., Demoe, J.H., Warrington, J.P., Yan, H., Nicolle, M.M., Towner, R., Sonntag, W.E., 2009. Basal and hypercapnia-altered cerebrovascular perfusion predict mild cognitive impairment in aging rodents. Neuroscience $164,918-928$

Murphy, A.C., Lalor, S.J., Lynch, M.A., Mills, K.H., 2010. Infiltration of Th1 and Th17 cells and activation of microglia in the CNS during the course of experimental autoimmune encephalomyelitis. Brain Behav. Immun. 24, 641-651.

Murphy, M.J., Grace, G.M., Tartaglia, M.C., Orange, J.B., Chen, X., Rowe, A., Findlater, K., Kozak, R.I., Freedman, M., Strong, M.J., Lee, T.Y., 2008. Cerebral haemodynamic changes accompanying cognitive impairment in primary lateral sclerosis. Amyotroph. Lateral Scler. 9, 359-368

Nolan, Y., Maher, F.O., Martin, D.S., Clarke, R.M., Brady, M.T., Bolton, A.E., Mills, K.H., Lynch, M.A., 2005. Role of interleukin-4 in regulation of age-related inflammatory changes in the hippocampus. J. Biol. Chem. 280, 9354-9362.

O’Donnell, E., Vereker, E., Lynch, M.A., 2000. Age-related impairment in LTP is accompanied by enhanced activity of stress-activated protein kinases: analysis of underlying mechanisms. Eur. J. Neurosci. 12, 345-352.

O'Shea, J.M., Williams, S.R., van Bruggen, N., Gardner-Medwin, A.R., 2000. Apparent diffusion coefficient and MR relaxation during osmotic manipulation in isolated turtle cerebellum. Magn. Reson. Med. 44, 427-432.

Pakulski, C., Drobnik, L., Millo, B., 2000. Age and sex as factors modifying the function of the blood-cerebrospinal fluid barrier. Med. Sci. Monit. 6, 314-318.

Parry, A., Clare, S., Jenkinson, M., Smith, S., Palace, J., Matthews, P.M., 2002. White matter and lesion T1 relaxation times increase in parallel and correlate with disability in multiple sclerosis. J. Neurol. 249, $1279-1286$.

Paxinos, G., Watson, C., 2004. The Rat Brain in Stereotaxic Co-Ordinates. Academic Press, New York.

Pelegrí, C., Canudas, A.M., del Valle, J., Casadesus, G., Smith, M.A., Camins, A., Pallàs, M., Vilaplana, J., 2007. Increased permeability of blood-brain barrier on the hippocampus of a murine model of senescence. Mech. Ageing Dev. 128, 522-528.

Popescu, B.O., Toescu, E.C., Popescu, L.M., Bajenaru, O., Muresanu, D.F., Schultzberg, M., Bogdanovic, N., 2009. Blood-brain barrier alterations in ageing and dementia. J. Neurol. Sci. 283, 99-106.

Reitz, C., Brickman, A.M., Brown, T.R., Manly, J., DeCarli, C., Small, S.A., Mayeux, R., 2009. Linking hippocampal structure and function to memory performance in an aging population. Arch. Neurol. 66, 13851392.
Roy, A., Jana, A., Yatish, K., Freidt, M.B., Fung, Y.K., Martinson, J.A., Pahan, K., 2008. Reactive oxygen species up-regulate CD11b in microglia via nitric oxide: Implications for neurodegenerative diseases. Free Radic. Biol. Med. 45, 686-699.

Schindowski, K., Eckert, A., Peters, J., Gorriz, C., Schramm, U., Weinandi, T., Maurer, K., Frolich, L., Muller, W.E., 2007. Increased T-cell reactivity and elevated levels of $\mathrm{CD}^{+}$memory T-cells in Alzheimer's disease-patients and T-cell hyporeactivity in an Alzheimer's diseasemouse model: implications for immunotherapy. Neuromol. Med. 9, $340-354$.

Schmitt, F., Grosu, D., Mohr, C., Purdy, D., Salem, K., Scott, K.T., Stoeckel, B., 2004. 3 Tesla MRI: successful results with higher field strengths [in German]. Radiologe 44, 31-47.

Shichita, T., Sugiyama, Y., Ooboshi, H., Sugimori, H., Nakagawa, R., Takada, I., Iwaki, T., Okada, Y., Iida, M., Cua, D.J., Iwakura, Y., Yoshimura, A., 2009. Pivotal role of cerebral interleukin-17-producing gammadeltaT cells in the delayed phase of ischemic brain injury. Nat. Med. 15, 946-950.

Sibson, N.R., Lowe, J.P., Blamire, A.M., Martin, M.J., Obrenovitch, T.P., Anthony, D.C., 2008. Acute astrocyte activation in brain detected by MRI: new insights into T(1) hypointensity. J. Cereb. Blood Flow Metab. 28, 621-632.

Siemonsen, S., Finsterbusch, J., Matschke, J., Lorenzen, A., Ding, X.Q., Fiehler, J., 2008. Age-dependent normal values of T2* and T2' in brain parenchyma. AJNR Am. J. Neuroradiol. 29, 950-955.

Small, S.A., Chawla, M.K., Buonocore, M., Rapp, P.R., Barnes, C.A., 2004. Imaging correlates of brain function in monkeys and rats isolates a hippocampal subregion differentially vulnerable to aging. Proc. Natl. Acad. Sci. U. S. A. 101, 7181-7186.

Stamatovic, S.M., Keep, R.F., Andjelkovic, A.V., 2008. Brain endothelial cell-cell junctions: how to "open" the blood brain barrier. Curr. Neuropharmacol. 6, 179-192.

Stone, D.K., Reynolds, A.D., Mosley, R.L., Gendelman, H.E., 2009. Innate and adaptive immunity for the pathobiology of Parkinson's disease. Antioxid. Redox Signal. 11, 2151-2166.

Teipel, S.J., Kaza, E., Hadlich, S., Bauer, A., Brüning, T., Plath, A.S., Krohn, M., Scheffler, K., Walker, L.C., Lotze, M., Pahnke, J., 2011. Automated detection of amyloid- $\beta$-related cortical and subcortical signal changes in a transgenic model of Alzheimer's disease using highfield MRI. J. Alzheimers Dis. 23, 221-237.

Tétrault, S., Chever, O., Sik, A., Amzica, F., 2008. Opening of the bloodbrain barrier during isoflurane anaesthesia. Eur. J. Neurosci. 28, 13301341.

Togo, T., Akiyama, H., Iseki, E., Kondo, H., Ikeda, K., Kato, M., Oda, T., Tsuchiya, K., Kosaka, K., 2002. Occurrence of T cells in the brain of Alzheimer's disease and other neurological diseases. J. Neuroimmunol. 124, 83-92.

van Es, A.C., van der Grond, J., ten Dam, V.H., de Craen, A.J., Blauw, G.J., Westendorp, R.G., Admiraal-Behloul, F., van Buchem, M.A., PROSPER Study Group, 2010. Associations between total cerebral blood flow and age related changes of the brain. PLoS One 5, e9825. van Walderveen, M.A., Kamphorst, W., Scheltens, P., van Waesberghe, J.H., Ravid, R., Valk, J., Polman, C.H., Barkhof, F., 1998. Histopathologic correlate of hypointense lesions on T1-weighted spin-echo MRI in multiple sclerosis. Neurology 50, 1282-1288. 